Çukurova Üniversitesi Mühendislik Mimarlık Fakültesi Dergisi, 31(1), 405-419 ss. , Haziran 2016

Cukurova University Journal of the Faculty of Engineering and Architecture, 31(1), pp. 405-419, June 2016

\title{
Uygulamalı Otomasyon Sistemleri Eğitim Simülatörü Geliştirilmesi
}

\author{
Erdoğan ŞİMŞEK*1, Orçun KÜÇÜKATAY ${ }^{2}$ \\ ${ }^{1}$ Çukurova Üniversitesi, Adana Meslek Yüksekokulu, Elektrik ve Enerji Bölümü, İklimlendirme \\ ve Soğutma Teknolojisi Programı, Adana \\ ${ }^{2}$ T.C MEB Çukurova Elektrik Mesleki ve Teknik Anadolu Lisesi, Endüstriyel Bakım ve \\ Onarm Dalı, Adana
}

Geliş tarihi: 10.02.2016 Kabul tarihi: 09.03.2016

\section{Özet}

Türkiye'de iş çevrelerinin ortak beklentisi, mesleki ve teknik okulların yetiştirdiği teknik elemanların piyasa ihtiyaçlarını karşılayabilir nitelikte olmasıdır. Baş döndürücü bir hızla gelişen otomasyon sektöründe oldukça ciddi seviyede nitelikli ara eleman açığ 1 bulunmaktadır. Türkiye'de otomatik kontrol konusunda nitelikli ara eleman ihtiyacını gidermek ancak bu konuda eğitim veren mesleki okullarda pratiğe yönelik eğitim yapılması ile mümkündür.

Uygulamalı Otomasyon Sistemleri Simülatörü, Mesleki ve Teknik Eğitim verilen tüm okul ve kurumların yanı sıra üretim yapan kurumların hizmet içi eğitim faaliyetlerinde de uygulamalı eğitim verebilmek üzere tasarlanmıştır. Uygulamalı Otomasyon Sistemleri Simülatörü mesleki ve teknik eğitim alan teknik personel adaylarının uygulama faaliyetlerini gerçekleştirebildiği ve yaptığı uygulamalar sayesinde farklı uygulamalar tasarlayabileceği bir eğitim materyalidir.

Sistem üzerinde endüstriyel üretimde kullanılan tüm elektriksel alıcıların minyatürleri üzerinde çeşitli uygulama örnekleri ve yazılımlar gerçekleştirilerek deney sonuçlarının gözlemlenmesini sağlayan materyaller mevcuttur. Böylece öğrenci ve kursiyerin sahada çalışmadan önce saha ortamına ön hazırlık safhası olabilecek ve kendisini geliştirerek fikir yürütebilecek bir eğitim ortamı sağlanmaktadır.

Uygulamalı Otomasyon Sistemleri Simülatörü piyasada bulunan tüm PLC markaları ile uyumlu çalışarak yazılan programların test edilmesi olanağını sunmaktadır. Aynı zamanda mikro denetleyici tabanlı kontrol kartları kullanılarak deneysel çalışmalar yapılabilmektedir. Mesleki ve teknik eğitimde başarıya ulaşmanın yolu, verilen teorik bilgilerin uygulama ve deney faaliyetleri ile desteklenmesi ile mümkündür. $\mathrm{Bu}$ set bu alandaki açı̆̆ı kapatabilecek niteliktedir.

Anahtar Kelimeler: Otomatik kontrol, Eğitim simülatörü, Mesleki eğitim, PLC

\footnotetext{
*Yazışmaların yapılacağı yazar: Erdoğan ŞìMŞEK, Çukurova Üniversitesi, Adana Meslek Yüksekokulu, İklimlendirme-Soğutma Programı, 01160Adana.esimsek@cu.edu.tr
} 


\title{
Development of an Applied Automation Systems Simulator
}

\begin{abstract}
The common expectations of the business world in Turkey are that the vocational schools of higher education and technical schools train students according to the needs of the industry. In the rapidly developing automation sector there is serious shortage of technically skilled personnel. The only way to provide the amount of skilled technical personnel up to the expectations of the industry can only be achieved by making the education in vocational schools oriented for the applied industry practice.
\end{abstract}

The developed Applied Automation Systems Simulator is designed to be used in vocational and technical schools and also can be used in enterprises in the industry for hands on training for the staff. This simulator is a training material that helps the technical personnel candidates who attend vocational education to participate applied activities and to design new applications on their own. There exist the miniatures of all the electrical sensors used in the industrial production systems on the simulator where students can participate in some predefined application examples, observe and gather info about experiments made by the students using the software in the simulator. Hence an educational environment where students can practice real life situations applied in the industry before going to the field can be created and the students can learn how to make reasoning in such situations by improving their skills.

The developed simulator is compatible with all the PLC brands used in the industry therefore giving the ability to test the programs written by the students in the software employed in the simulator. At the same time by the use of microcontroller based control cards experimental studies can easily be made with the simulator. The way to success in vocational and technical education is only possible by reinforcing the theoretical education with hands on activities and experiential training. This simulator is capable of filling the gap in this field.

Keywords: Automatic control, Training simulator, Vocational education, PLC

\section{GİRIS}

Türkiye'de iş piyasasının mesleki ve teknik eğitim veren kurumlardan beklentisi, iş ihtiyaçlarını karşılayabilen nitelikli teknik elemanların yetiştirmesidir. Ülkemizin satın alıp tüketen ülke konumundan çıkıp üreten ve ürettiği ürünleri tüm dünya ülkelerine pazarlayan ülke konumuna geçmesi, üretim safhalarında görev alan teknik elemanların mesleki yeterliliği ile doğrudan ilişkilidir [1]. Bu doğrultuda mesleki eğitim alan öğrenci ve kursiyerlerin mesleğin gerektirdiği bilgi beceri ve uygulama yeteneklerine tamamen sahip olmaları gerekmektedir. Ayrıca mesleki eğitim alan teknisyen adaylarının öğrendikleri teorik bilgileri uygulama yapmadan direkt olarak saha ortamında tecrübe etmesi iş kazası ya da ekonomik kayıplara sebep olacağından kesinlikle kabul edilemez bir durumdur [2]. Öğrenme yöntemleri üzerine yapılan araştırma sonuçlarına gore, uygulamalı eğitim yöntemleri kullanarak yapılan eğitim faaliyetlerinde $\% 90$ lara varan öğrenme verimliliği gözlemlenmiştir. Dolayısıyla mesleki eğitimde etkili bir eğitim ortamı olması için teorik bilgilerin uygulama ve deney faaliyetleri ile desteklenmesi gerekliliği unutulmamalıdır $[3,4]$. $\mathrm{Bu}$ eğitim seti; mesleki eğitim alan bireylerin motor kontrolü, motor sürücü kullanımı, endüstriyel sensor kullanımı, proses kontrol cihazları kullanımı, elektro-pnömatik sistemlerin kontrolü, trafik 1șıkları simülatörü gibi endüstriyel ortamlarda kullanılan cihazlarla ilgili yüzlerce deney gerçekleştirerek daha etkin bir öğrenim ortamı sağlamak amaciyla tasarlanmıștır. Eğitim simülatörüne tüm marka PLC üniteleri ve mikrodenetleyici tabanlı kartlar bağlanabilmektedir. Otomasyon sistemleri uygulamaları eğitim simülatörü, mesleki 
eğitim alan öğrenci ve kursiyerlerin mikrodenetleyici kartları ya da PLC cihazı ile bilgisayar ortamında hazırladıkları otomatik kontrol yazılımlarını eğitim simülatörü üzerinde test etme olanağı sağlamaktadır. Eğitim simülatörü içeriğinde üç fazlı asenkron motorlar, pnömatik ve elektropnömatik valfler, endüstriyel sensörler, proses kontrol cihazları, pt100 sicaklık elemanları, minyatür trafik sinyalizasyon uygulamaları, motor sürücü motor devir sayacı uygulamaları ile ilgili yüzlerce birbirinden farklı deney ve uygulama yapılabilmektedir. Söz konusu uygulamalar, öğrenci ve kursiyerlerin endüstriyel üretimde karşılaşacakları hemen hemen tüm ekipman ve cihazların kullanımını deneyimlemelerini sağlayacaktır. Uygulamalı otomasyon sistemleri eğitim simülatörü, piyasada bulunan tüm PLC modelleri ve mikrodenetleyici kontrol kartlarının bağlantı şekline uyumludur. Ayrıca mesleki eğitim alan öğrenci ve kursiyerlerin güvenli bir şekilde deney yapabilmeleri için bağlantı yapılan tüm noktalar insan sağlığını tehdit etmeyen 24V DC gerilim ile kontrol edilmektedir. Otomatik kontrol uygulamaları eğitim simülatörü üniversitelerin Makine, Elektrik-Elektronik, Mekatronik ve PLC ders müfredatı olan bölümleri, Meslek Yüksekokulları ve Meslek Liselerinin bölümlerindeki mesleki eğitim uygulamalarında bu simülatör kullanılabilir. Ayrıca endüstriyel üretim yapan imalathane, fabrika, teknik servis gibi işletmelerin kendi bünyelerindeki hizmet içi eğitim faaliyetlerinde de kullanılabilmektedir $[5,6]$.

\section{MATERYAL VE METOD}

$\mathrm{Bu}$ eğitim setini gerçekleştirmek için ilk etapta $30 \mathrm{mmx} 30 \mathrm{~mm}$ profil kullanılarak $275 \mathrm{~cm} \times 75 \mathrm{~cm}$ boyutlarında bir masa hazırlanmıştır. Daha sonra $104 \mathrm{~cm} \mathrm{x} 272 \mathrm{~cm}$ boyutlarında bir stand hazırlanarak masaya monte edilmiştir. Masa ve stand $8 \mathrm{~mm}$ kalınlığındaki MDF malzeme ile kaplanmıştır. Sistemlere ait ekipmanlar için MDF levha üzerinde gerekli kanallar açılmıştır. Cihazlar yerine yerleştirilerek sağlamlıkları kontrol edilmiştir. Sistemin 220 ve 380 volt elektrik girişleri gerçekleştirilmiştir. Herhangi bir nedenle sistemler üzerinden tasarlanandan daha fazla akım geçmesi veya kısa devre durumunda tüm sistemin elektriğinin kesilmesi için gerekli koruyucular sisteme bağlanmıştır. Eğitim seti çalışmalarının bir bölümü Çukurova Üniversitesi, Adana Meslek Yüksekokulu, İklimlendirme ve Soğutma Teknolojisi Programı laboratuvarlarında ve TC MEB Çukurova Elektrik Mesleki ve Teknik Anadolu Lisesi, Endüstriyel Bakım ve Onarım Dalı laboratuvarlarında imal ve monte edilmiştir. Şekil 1'de otomasyon sistemleri uygulamaları eğitim simülatörünün imal edilmiş şekli gösterilmiştir.

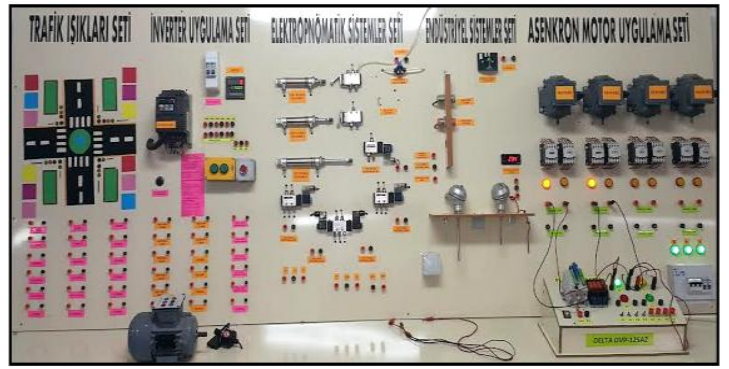

Şekil 1. Uygulamalı otomasyon sistemleri eğitim simülatörü

Bireylerin motor kontrolü, motor sürücü kullanımı, endüstriyel sensor kullanımı, proses kontrol cihazları kullanımı, elektro-pnömatik sistemlerin kontrolü, trafik 1şıkları simülatörü gibi endüstriyel ortamlarda kullanılan cihazlarla ilgili yüzlerce deney gerçekleştirerek bu setin kullanımı üniteler halinde aşağıda açıklanmıştır.

\subsection{Asenkron Motor Kontrol Ünitesi}

Asenkron motor kontrol ünitesinin montajlı resmi Şekil 2'de gösterilmiştir.

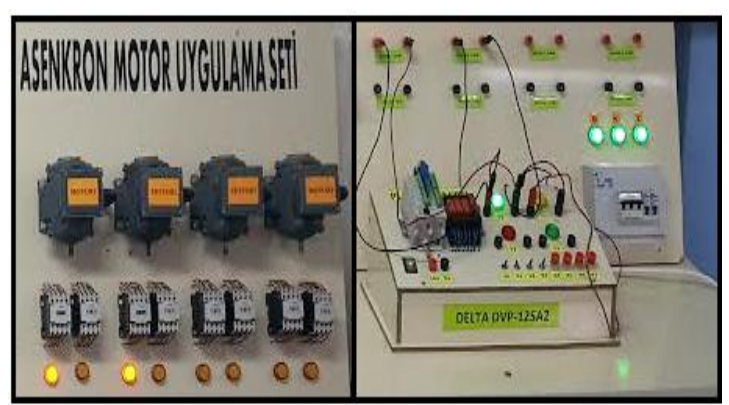

Şekil 2. Asenkron motor kontrol ünitesi montaj resmi 
Şekil 4’te asenkron motor kontrol ünitesi güç devresi gösterilmiştir. Asenkron motor kontrol ünitesinde kullanılan elemanların teknik özellikleri Çizelge 1'de gösterilmiştir. Sistemde kullanılan motorlar 3 fazlı $0,20 \mathrm{~kW}$ gücündedir. Her bir motor için iki adet kontaktör kullanılmıştır. Kontaktörlerden biri motoru ileri yönde, diğeri ise geri yönde çalıştırmak için kullanılmıştır. Kontaktörlerin alt kısmına yerleştirilmiş olan sinyal lambaları ise ilgili kontaktörün çalışıp çalışmadığını göstermek amaçlıdır.
Ayrica sistemde 8 adet 24 volt DC röle kullanılmıștır. $\mathrm{Bu}$ röleler kontaktörleri $24 \mathrm{~V}$ DC bobin gerilimi ile sürmek amaciyla sisteme ilave edilmiştir. Kontaktörlerin altında ise PLC ya da mikro denetleyici bağlantılarının pratik bir şekilde bağlanabilmesi için born vida bağlantı uçları montajlanmıştır.

Şekil 3'te asenkron motor kontrol ünitesi kumanda devresi gösterilmiştir.

Çizelge 1. Asenkron motor kontrol ünitesinin teknik özellikleri

\begin{tabular}{|c|c|c|c|}
\hline Malzeme Ad1 & Ad. & Teknik özellik & Görevi \\
\hline $\begin{array}{l}\text { Asenkron } \\
\text { Motor }\end{array}$ & 4 & $0,20 \mathrm{~kW} 3 \mathrm{Faz}$ & $\begin{array}{l}\text { Stator sargısına uygulanan gerilimi hareket enerjisine } \\
\text { çevirmek }\end{array}$ \\
\hline Kontaktör & 8 & $1,1 \mathrm{kw} 3 \mathrm{NO} 2 \mathrm{NC}$ kontak & Asenkron motorların ileri geri yönde hareketini sağlamak \\
\hline $\begin{array}{l}\text { Sinyal } \\
\text { Lambas1 }\end{array}$ & 8 & $220 \mathrm{~V}$ AC Led & İlgili kontak enerjilendiğinde 1 şıkla uyarı vermek \\
\hline Röle & 8 & 24V DC Çift Kontak & Kontaktörlerin 24V DC ile sürülmesini sağlamak \\
\hline
\end{tabular}

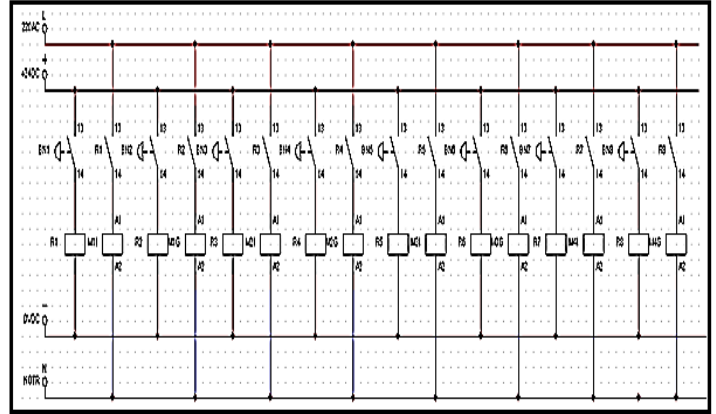

Şekil 3. Asenkron motor kontrol ünitesi kumanda devresi

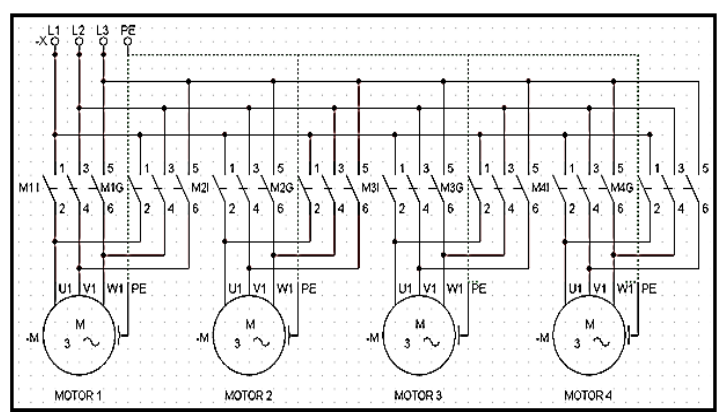

Şekil 4. Asenkron motor kontrol ünitesi güç devresi
Üç fazlı sigortadan gelen RST fazları, dört adet motorun ileri geri kontrolü için kullanılan sekiz adet kontaktörün güç kontaklarına giriş yapılır. Motoru ileri yönde hareket ettirmek için 1, 3, 5, 7 nolu kontaktörlerin güç kontağı çıkış uçları asenkron motor klamens kutusundaki U,V,W uçlarına sırasıyla bağlantı yapılır. Motorların ters yöne hareketleri için ise fazın biri sabit tutulup herhangi iki fazın yerleri değiştirilmesi prensibine göre 2, 4, 6, 8 nolu kontaktörlerinin 1 nolu güç kontağ1 sabit tutulup $U$ fazına, kontaktör 2 nolu güç kontağ $1 \mathrm{~W}$ ucuna, 3 nolu kontaktör güç kontağ1 çıkışı da $\mathrm{V}$ fazına bağlanmıştır. Bu şekilde geri yönde motor kontrolü için ilk faz sabit bırakılıp diğer iki faz ters çevrilerek motorun ters yönde çalışmasını sağlayacak bağlantılar gerçekleştirilmiştir.

Otomasyon sistemleri uygulama seti üzerinde herhangi bir motoru ileri ya da geri yönde çalıştırmak için simülator seti üzerinde bulunan ilgili born vidaları karşılıklı olarak kısa devre edilir. $\mathrm{Bu}$ şekilde motor istenilen yönde kontrol edilmiş olur. Born vidaları üzerinde güvenlik risklerini minimize etmek için $24 \mathrm{~V}$ DC gerilim kullanılır. $\mathrm{Bu} 24$ voltuk $\mathrm{DC}$ gerilim ilgili 
kontaktöre bağlı olan röleyi enerjilendirerek kontaktörün çekmesi için gerekli olan faz gerilimini A1 ucuna uygulamış olur.

\subsection{1. Örnek Uygulama:1(PLC Kullanılarak Çözüm)}

$\mathrm{Bu}$ otomasyon sisteminde iki adet start butonu, bir adet stop butonu bulunmaktadır. Birinci start butonuna basılınca 1 ve 2 nolu motorlar ileri yönde hareket edecek; 3 ve 4 nolu motorlar çalışıyor ise duracaktır. İkinci start butonuna basılınca üçüncü motor geri yönde çalışmaya başlayacak, 10 sn sonra dördüncü motor da geri yönde çalışmaya başlayacaktır. Stop butonuna basılınca tüm motorlar duracaktır. PLC kullanılarak çözüm Şekil 5 'te gösterilmiştir.

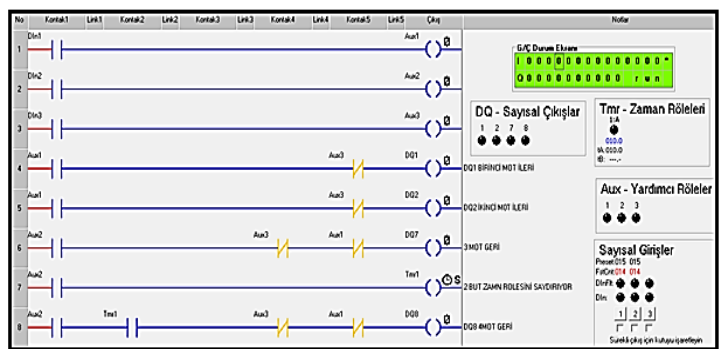

Şekil 5. PLC kullanılarak çözüm

Şekil 5'e ait bir PLC uygulama yazılımı aşağıda gösterilmiştir. Ayrıca uygulamaya ait PLC giriş çıkış uçları Çizelge 2 'de verilmiştir.

PLC yazılımında kontak konumları tasarımı da Çizelge 2'de belirtilmiștir. Kullanıcı uygun PLC yazılımını gerçekleştirdikten sonra yazılımı PLC cihazına yükleyip PLC'nin uygun born çıkışlarını, kablo jakları vasıtasıyla eğitim simülatörü üzerine bağlantı yaparak yazılımını test edecektir.

Her öğrenci veya kullanıcı, uygulama deneylerinde problemin çözümüne yönelik gerekli yazılımı, kendi bireysel çabaları ile gerçekleştirmelidir.

\subsection{2. Örnek Uygulama: 2 (Mikrodenetleyici Kart Kullanılarak Çözüm)}

Uygulama 2'de görülen mikro denetleyici kart kullanarak çalışma gerçekleştirilmiştir.
Şekil 7'de mikro denetleyici kart kontrol devresi gösterilmiştir.

Çizelge 2. Uygulamaya ait PLC giriş çıkış uçları

\begin{tabular}{|c|c|}
\hline $\begin{array}{c}\text { Mikrodenetleyici giriş-çıkış } \\
\text { adı }\end{array}$ & İlgili bağlantı \\
\hline D0 & 1.motor ileri çıkış1 \\
\hline D1 & 2.motor ileri çıkış1 \\
\hline $\mathrm{D} 2$ & 3.motor ileri ç1k1ş1 \\
\hline B0 & 1.motor ileri çıkışı \\
\hline B1 & 2.motor ileri çıkışı \\
\hline B2 & 3.motor ileri çıkış1 \\
\hline B3 & 4.motor ileri çıkış1 \\
\hline B4 & 1.motor geri ç1k1ş1 \\
\hline B5 & 2.motor geri çıkış1 \\
\hline B6 & 3.motor geri çıkış1 \\
\hline B7 & 4.motor geri çıkış1 \\
\hline
\end{tabular}

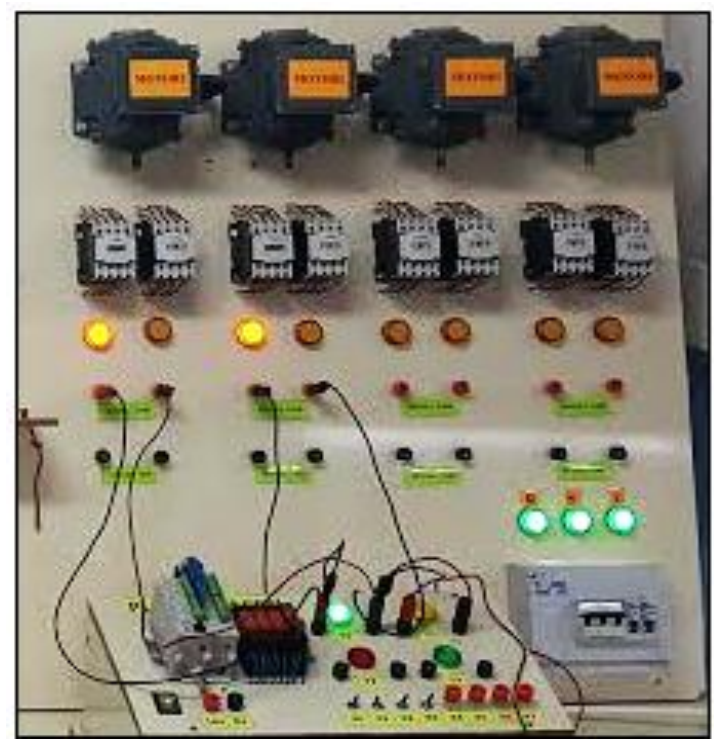

Şekil 6. PLC cihazı ile eğitim simülatörü bağlantıs1

Uygulamaya ait mikrodenetleyici giriş çıkış uçları Çizelge 3 'te gösterilmiştir.

Otomasyon sistemleri uygulamaları eğitim simülatörü kullanarak öğrenci ve kursiyerler, aynı problemin çözümünü PLC cihazı yerine Mikrodenetleyici kart kullanarak da çözebilirler. Problemin çözümüne yönelik tasarlanan Mikro Denetleyici yazılım, kart üzerine yüklenmeden 
önce yukarıdaki gibi bir simülasyon programı ile test edilebilir.

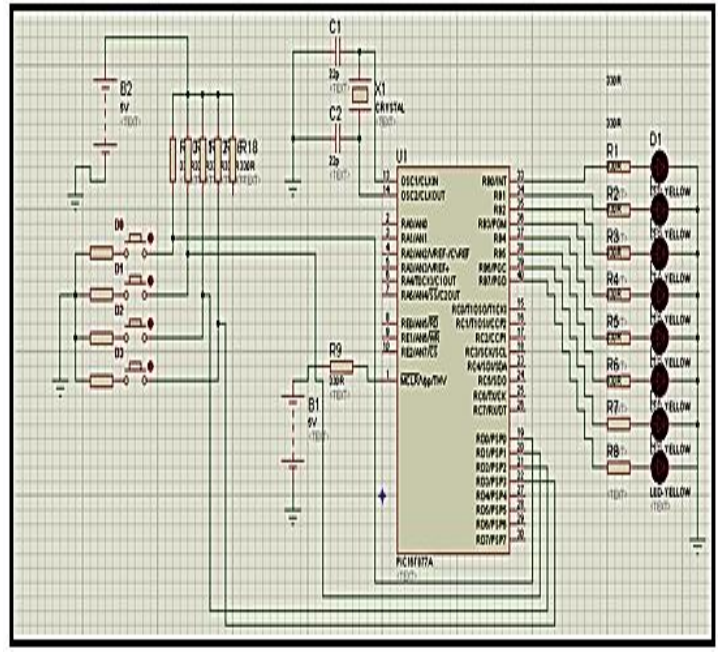

Şekil 7. Mikrodenetleyici kart kontrol devresi

Çizelge 3. Uygulamaya ait mikrodenetleyici giriş çıkış uçları

\begin{tabular}{|c|c|}
\hline $\begin{array}{c}\text { PLC giriş çıkı̧̧ } \\
\text { adı }\end{array}$ & İlgili bağlantı \\
\hline DQ1 & 1.motor ileri çıkış1 \\
\hline DQ2 & 2.motor ileri çı1ş1 \\
\hline DQ3 & 3.motor ileri ç1k1ş1 \\
\hline DQ4 & 4.motor ileri çı1ş1 \\
\hline DQ5 & 1.motor geri ç1kş̧1 \\
\hline DQ6 & 2.motor geri çı1ş1 \\
\hline DQ7 & 3.motor geri çı1ş1 \\
\hline DQ7 & 4.motor geri ç1kış1 \\
\hline DIN1 & PLCbirinci start butonu \\
\hline DIN2 & PLC ikinci start butonu \\
\hline DIN3 & PLC stop butonu \\
\hline
\end{tabular}

Simülatör ile test edilen yazılım daha sonra Mikrodenetleyici entegresine yüklenir, kart ve eğitim simülatörü arasındaki kablo jack bağlantıları yapılır, sonunda problem çözümüne yönelik yazılım, eğitim simülatörü ile çalıştırılır. Uygulamaya ait mikrodenetleyici yazılımı aşağıdadır: \#include <16F877A.h>

\#fuses XT,NOWDT,NOPROTECT

\#use delay (clock=4000000)

void main()

\{

set_tris_d(0b11111);// d portları giriş olarak ayarland 1

set_tris_b(0b00000000); b portları çıkış olarak ayarland 1

tekrar:

output_b(0);// tüm çıkışlar pasif

IF(input(PIN_D3)==1 \&\& input(PIN_D2)==1 \&\&

input(PIN_D1) $==1$

$\& \&$ input(PIN D0)==1)//hiçbir butona basılmazsa

\{

output_b(0); //tüm çıkışlar sıfır

\}

IF(input(PIN_D3)==1 \&\& input(PIN_D2) $==1 \& \&$ input $($ PIN_D1 $)==1 \& \&$ input $($ PIN_D0) $==0) / /$ d0 birinci butona basılirsa

\{

output_b(3); //b0 ve b1 çıkışları aktif 1ve 2 mot ileri yönde çalıştırır.

delay_ms(10);

goto tekrar;

\}

IF(input(PIN_D3) $==1 \& \&$ input(PIN_D2) $==1 \& \&$ input(PIN_D1 $)==0$ \&\& input(PIN_D0)==1)// d1 ikinci butana basılırsa \{

output_b(64); //b7 2sn sonra b8 aktif 3.motor geri yönde çalışır

delay_ms(1000);//1sn bekleme

delay_ms(1000);//1sn bekleme

output_b(192);///2 sn sonra b7 ve b8 çıkıları aktif 3 . ve 4. Motor geri yönde

delay_ms(10);

goto tekrar;

\}

IF(input(PIN_D3) $==1 \& \&$ input(PIN_D2) $==0 \& \&$ $\operatorname{input}\left(\mathrm{PIN} \_\mathrm{D} 1\right)==1 \quad \& \& \quad$ input(PIN_D0) $\left.==1\right) / / \mathrm{d} 2$ stop butonu

\{

output_b(0);// tüm çıkışlar pasif

delay_ms(10);

goto tekrar;

\} 


\subsection{Endüstriyel Sensör Sistemleri Simülatörü}

Endüstriyel sensör sistemleri uygulama simülatörünün montajlı resmi Şekil 8'de gösterilmiştir.

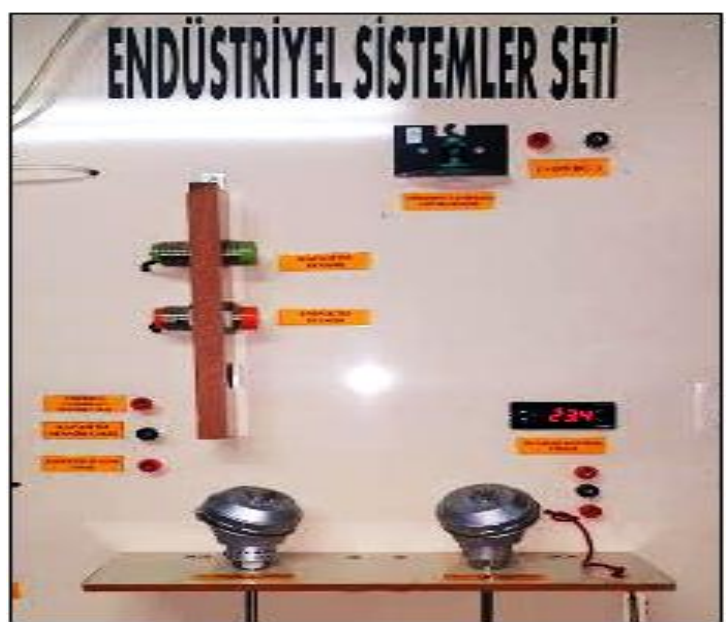

Şekil 8. Endüstriyel sensor sistemleri uygulama simülatörünün montaj resmi

Endüstriyel Sensör Sistemleri uygulama simülatörü içeriğinde; kapasitif sensör, endüktif sensör, optik sensör pt100 kafa tip sicaklık sensörleri, ntc sicaklık sensörü, proses kontrol cihazları gibi endüstriyel üretimde kullanılan sensör ve proses kontrol cihazları bulunmaktadır. Bu cihazlar ile öğrenci, kursiyer ya da teknik personel adayları, çeşitli uygulama deneyleri yaparak teorik bilgilerini uygulama imkânı yakalamaktadırlar. Simülatör üzerinde bulunan proses kontrol cihazına set üzerinde mevcut sensörlerin bağlantısı yapılıp parametre değerleri girilerek çok çeşitli uygulamalar yapılabilmektedir.

Çizelge 4'te endüstriyel sensör sistemleri simülatörüne ait malzemeler, adetleri, kullanılan malzemelerin teknik özellikleri ve görevleri verilmiştir. Endüstriyel sensör sistemlerine ait sensörlerin büyük bir kısmı 24V DC gerilim ile çalışmaktadır. Sistem üzerinde bulunan sensörlerin üç ucu bulunmaktadır. Bu uçlardan iki tanesi +$24 \mathrm{~V}$ besleme uçları, diğer ucu ise' Q adı verilen çıkış ucudur. Sensör, ortamdaki fiziksel değişimi algıladığında aktifleşerek $0 \mathrm{~V}$ olan enerji potansiyelini $+24 \mathrm{~V}$ değerine çıkarmaktadır. Bu çıkış sinyali direkt olarak bir motoru sürmek için yeterli değildir. Q çıkışı bir PLC cihazına ya da mikrodenetleyici kartına giriş bilgisi olacak şekilde kullanılmak üzere uygulanır.

Ayrıca Simülatör üzerinde bulunan proses kontrol cihazı ile sensörlerden okunan değer set değeri ile kıyaslanarak proses kontrol cihazının çıkışı aktif edilebilir.

\subsection{1. Örnek Uygulama (PLC cihazı kullanılarak)}

Bir otomasyon sisteminde endüktif sensöre metal

Çizelge 4. Endüstriyel sensör sistemleri simülatörü teknik özellikleri

\begin{tabular}{|c|c|c|c|}
\hline Malzeme Ad1 & Adet & Teknik özellik & Görevi \\
\hline Kapasitif Sensör & 1 & 24V DC 30mA PNP çıkış & $\begin{array}{l}\text { Sensör 20mm yakınına herhangi bir } \\
\text { cisim yaklaştığında Q çıkışı aktif olur. }\end{array}$ \\
\hline Endüktif Sensör & 1 & 24V DC 30mA PNP çıkış & $\begin{array}{l}\text { Sensör 20mm yakınına metal bir cisim } \\
\text { yaklaştığında Q çıkışı aktif olur. }\end{array}$ \\
\hline Optik Sensör & 1 & 24V DC 30mA NPN çıkış & $\begin{array}{l}\text { Sensör optik gözüne herhangi bir cisim } \\
\text { yaklaştığında } 24 \mathrm{vdc} \text { olan Q çıkışı 0v } \\
\text { potansiyeline düşer. }\end{array}$ \\
\hline Ntc Sensör & 1 & $-50-200 \mathrm{C}$ algilama & Ortam sıcaklık değerini algılama \\
\hline Proses Kontrol Cihazı & 1 & $220 \mathrm{~V}$ AC çalışma 2 adet röle çıkış & $\begin{array}{c}\text { Bağlanacak sensör ve girilen } \\
\text { parametrelere göre röle çıkışları aktif } \\
\text { olur. }\end{array}$ \\
\hline Pt100 Kafa tip & 1 & -200 C $600 \mathrm{C}$ arası sıcaklık ölçüm & $\begin{array}{l}\text { Proses kontrol cihazı ile birlikte } \\
\text { kullanılarak sıcaklığa bağlı uygulamalar } \\
\text { gerçekleștirmek. }\end{array}$ \\
\hline
\end{tabular}


bir cisim yaklaştırıldığında 1 numaralı motorun çalışması isteniyor. Kapasitif sensöre herhangi bir cisim yaklaştırdığında 1 numaralı motor duracak 2 numaralı motorun çalışması için uygun PLC yazılımları ile sistemi çalıştıralım. Endüktif sensör Q çıkışı PLC cihazının DIN1 girişine, kapasitif sensör DIN2 girişine birinci motor DQ1 çıkışına ikinci motor DQ2 çıkışına bağlanmıştır. Şekil 9'da PLC kullanılarak çözüm gösterilmiştir.

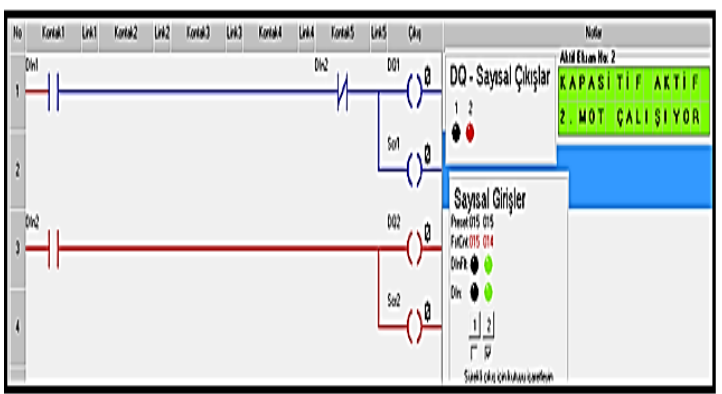

Şekil 9. PLC kullanılarak çözüm

\subsection{Elektropnömatik Sistemler Uygulama Simülatörü}

Elektropnömatik sistemleri uygulama simülatörünün montajlı resmi Şekil 10 'da gösterilmiştir.

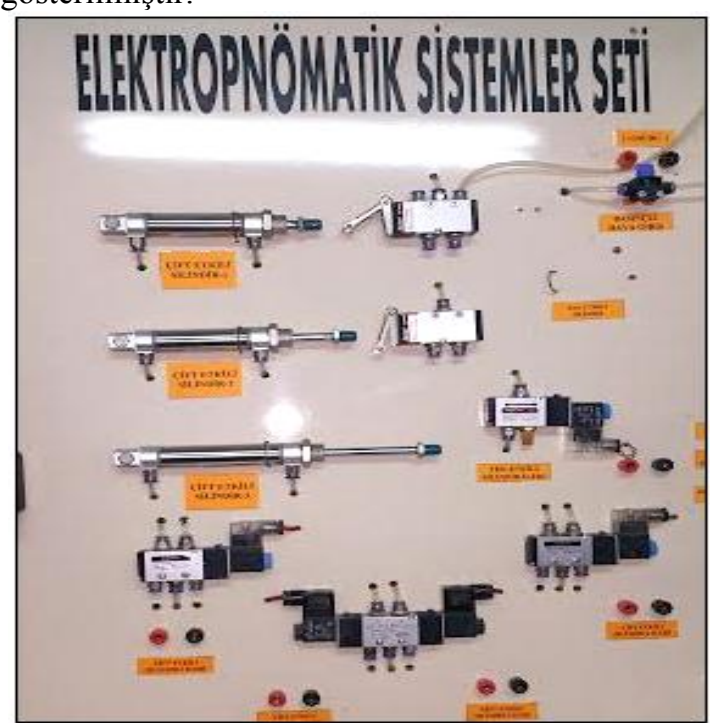

Şekil 10. Elektropnömatik sistemleri uygulama simülatörünün montajlı resmi
Sistem üzerinde bulunan üç adet çift etkili silindir, doğrusal hareket kaynağı olarak kullanılmaktadır. Silindirlere doğrusal hareketi kazandırmak için kullanılan yön kontrol valflerinin tamamı elektriksel sinyal ile kontrol edilmektedir. Pnömatik sistemlerin kontrolü için kullanılan basınçlı havanın temini için kompresör kullanılmıştır. Kompresörden alınan basınçlı hava; yağlayıcı, temizleyici, şartlandırıcı gibi ekipmanlardan geçirilerek basınçlı havanın uygun standartlara getirilmesi sağlanmıştır. Şekil 11'de elektropnömatik sistemlere ait devre şeması gösterilmiştir.

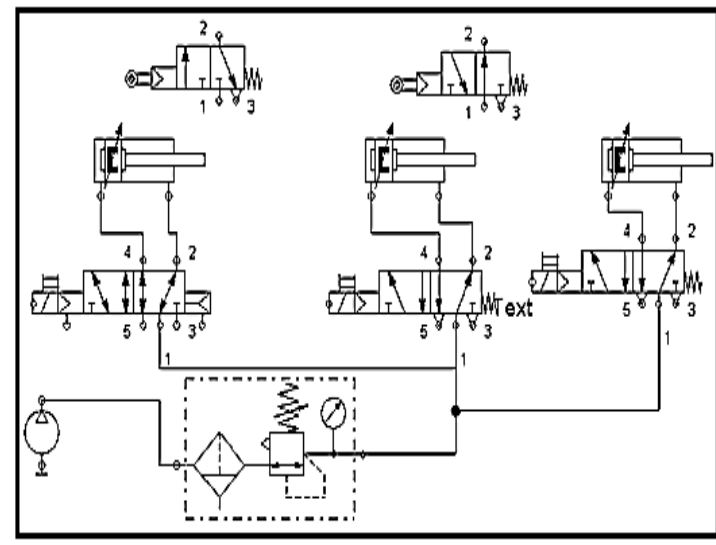

Şekil 11. Elektropnömatik sistemler devre şemas1

Sistemde kullanılan elemanların adetleri, teknik özellikleri ve bu elemanların görevleri Çizelge 5'de gösterilmiştir. Kullanılan çift etkili silindirler yastıklı tip seçilerek piston dip noktaya vurduğunda pistonun daha az gürültü ve vuruntu yapması sağlanmıştır. 3/2 makara valflar ile pistonlardan birinin hareketini tamamlamas1 durumunda diğer pistona hareket verilmesini sağlamaktadır. Yön kontrol valflerine 24 volt DC gerilim uygulanarak valfin konum değişimi sağlanarak pnömatik pistonların ters yöne hareketi sağlanır. Sistem üzerinde kullanılan basınçlı havanın hazırlanması için şartlandırıcı adı verilen kullanılan havayı temizleme yağlama ve uygun basınç değerine düşürme görevini yapan eleman kullanılmıştır. Bu şekilde pnömatik malzemelerin daha verimli şekilde çalışması sağlanmış olur. 
Çizelge 5. Elektropnömatik sistemler simülatörü teknik özellikleri

\begin{tabular}{|c|c|c|c|}
\hline Malzeme Adı & Ad. & Teknik özellik & Görevi \\
\hline Çift etkili silindir & 3 & $20 \mathrm{~mm}$ Yastıklı & Doğrusal hareket temini. \\
\hline Makara valf & 2 & $3 / 2$ makara valf & $\begin{array}{c}\text { Pistonların konum bilgisini almak için } \\
\text { kullanılmıştır. }\end{array}$ \\
\hline Yön kontrol valfi & 1 & 24V DC 5/2 çift bobinli valf & $\begin{array}{c}\text { Çift etkili silindirlerin çalışması için gerekli basınçlı } \\
\text { havayı yönlendirmek }\end{array}$ \\
\hline Yön kontrol valfi & 2 & 24V DC 5/2 tek bobinli valf & $\begin{array}{c}\text { Çift etkili silindirlerin çalışması için gerekli basınçlı } \\
\text { havayı yönlendirmek }\end{array}$ \\
\hline Yön kontrol valfi & 1 & 24V DC 3/2 tek bobinli valf & $\begin{array}{c}\text { Çift etkili silindirlerin çalışması için gerekli basıçlı } \\
\text { havayı yönlendirmek }\end{array}$ \\
\hline Hava hazırlayıcı & 1 & $\begin{array}{c}\text { Temizleme, yağlama ve } \\
\text { basınç değerini düzenleme }\end{array}$ & $\begin{array}{c}\text { Pnömatik elemanların çalışabilmesi için gerekli } \\
\text { basınçlı hava şartlarını sağlamak . }\end{array}$ \\
\hline
\end{tabular}

Elektropnömatik sistemler simülatörü ile öğrenci ve kursiyerler, endüstriyel ortamlarda kullanılan pnömatik pistonların kontrolü ile ilgili deney ve uygulama çalışmaları yapabilmektedirler. Sistem üzerinde bulunan selonoid valflere uygun hava hortumları bağlantıları yapılarak pnömatik pistonların PLC cihazı ya da mikrodenetleyci kartlar ile çalıștırılması sağlanmıș olur.

Pnömatik pistonlara bağlı olan yönlendirme valfleri 24V DC gerilim ile çalışmaktadır. Valflerin çalışması için gerekli elektriksel bağlantı yapilırken valfe negatif besleme direkt olarak verilip pozitif besleme valfe bağlı olan born vidası kablo jack bağlantıları ile gerçekleştirilmektedir.

\subsubsection{Elektropnömatik Sistemler Simülatörü Uygulaması}

Pnömatik valflerin kullanıldığı bir otomasyon sisteminde, birinci start butonuna basıldığında 1 nolu çift etkili silindir ileri yönde çalışırken ikinci start butonuna basıldığında ikinci çift etkili silindirin geri yönde çalıştırılması isteniyorsa, cisimden yansımalı optic sensör aktif olmalıdır. İkinci çift etkili silindir ileri yönde, endüktif sensör, aktif olduğunda ise ikinci çift etkili silindir geri yönde çalışacaktır. Uygulamaya ait PLC yazılımı Şekil 12'de gösterilmiştir.

PLC yazılımı olarak ikinci uygulamadan farklı bir PLC cihazı kullanıldığından programlama arayüzü ve giriş çıkış isimleri farklı isimler almıştır. PLC'nin x0 girişi birinci buton, $x 1$ girişi ikinci buton $\mathrm{x} 3$ butonu endüktif sensor, $\mathrm{x} 4$ butonu kapasitif sensor girişi olarak kullanılmıştır. PLC y0 çıkışı birinci piston ileri, y1 çıkışı birinci piston geri, y2 çıkış1 ikinci piston ileri, y3 çıkışı ikinci piston geri olacak şekilde gerekli kablo jack bağlantıları yapılarak uygulama çalıştırılabilir.

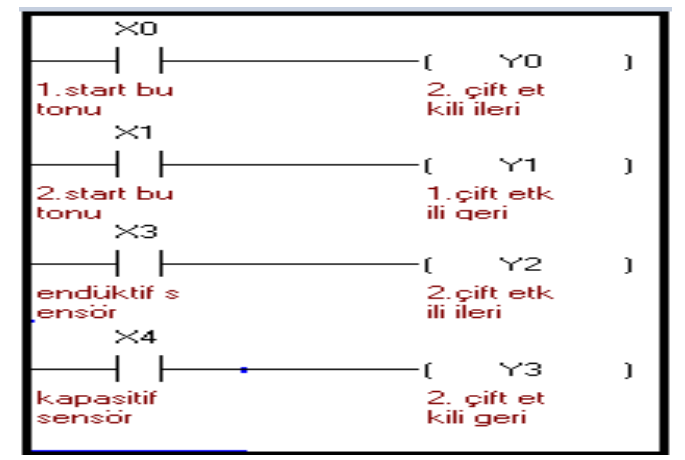

Şekil 12. Elektropnömatik sistemler simülatörü uygulaması PLC yazılımı

\section{4. İnverter Sistemleri Eğitim Simülatörü}

İnverter sistemleri eğitim simülatörünün montajlı resmi Şekil 13'de gösterilmiştir.

Sistemde kullanılan elemanların adetleri, teknik özellikleri ve bu elemanların görevleri Çizelge 6'da gösterilmiştir. Sistemde kullanılan inverter ile set üzerinde dahili olan üç fazlı asenkron motor kontrol edilebilmektedir. Motorun çalışma yönü, start butonuna basıldıktan sonra maksimum devire ulaşma zamanı, motor çalışıyor iken stop butonuna basılınca durma zamanı rampa değeri, değişik frekans değerlerinde motorun çalıştırılması, motorun harici start stop 
butonlarıyla kontrol edilebilmesi, motor üzerinde bulunan dahili butonlar ile start stop yapma, motor hızının eğitim seti üzerinde bulunan harici potansiyometre ile kontrolü, inverter üzerinde bulunan harici klamensler ile set üzerinde bulunan herhangi bir sensor bağlantısı ile çalıştırılması, durdurulması ya da motorun devir sayısının değiştirilmesi gibi uygulamalar yapılıp bir PLC ya da mikrodenetleyici kartı ile sistemin kontrolü sağlanabilir.

\subsection{1. Ínverter Sistemleri Eğitim Simülatörü Bağlantı Şeması}

Şekil 14'te sistemde kullanılan inverterin bağlantı şeması görülmektedir. İnverter cihazına giriş olarak tek fazlı $220 \mathrm{~V}$ AC gerilim uygulanmakta, çıkış olarak üç fazlı $220 \mathrm{~V}$ AC gerilim elde edilmektedir.

İnverter üzerinde dahili start stop butonları bulunduğu gibi motor çalışma hızını belirleyen dahili potansiyometre de bulunmaktadır.

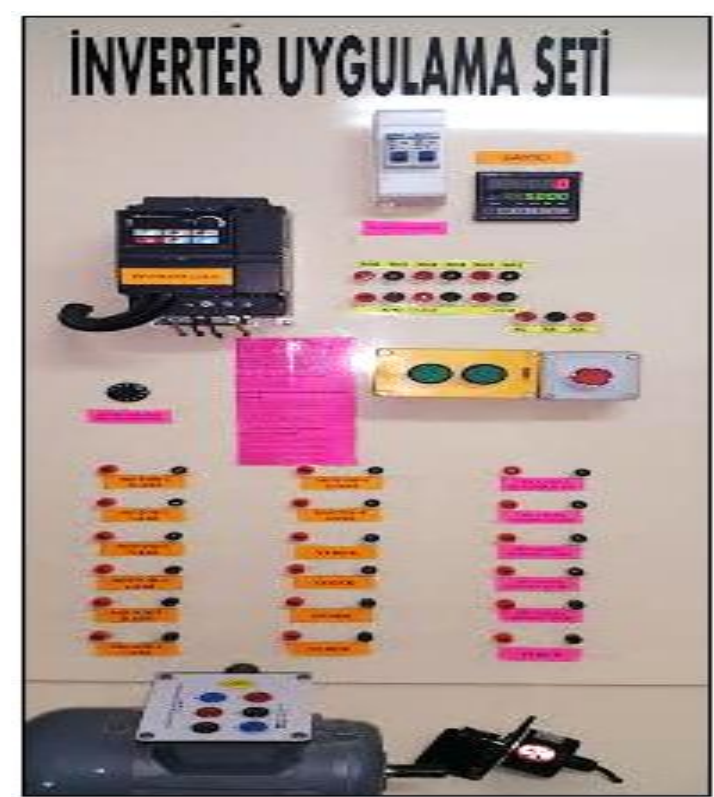

Şekil 13. İnverter sistemleri eğitim simülatörünün montajlı resmi

Çizelge 6. İnverter sistemleri eğitim simülatörü teknik özellikleri

\begin{tabular}{|c|c|c|c|}
\hline Malzeme Ad1 & Ad. & Teknik özellik & Görevi \\
\hline İnverter & 1 & $\begin{array}{c}2,2 \mathrm{KW} 220 \mathrm{~V} \text { AC } \\
\text { Giriş }\end{array}$ & Asenkron motoru istenilen frekans değerlerinde çalıştırmak \\
\hline $\begin{array}{c}\text { Asenkron } \\
\text { motor }\end{array}$ & 1 & $2880 \mathrm{~d} / \mathrm{dak} 2,2 \mathrm{KW}$ & İnverterden gelen frekans değerlerine göre motoru çalıştırmak. \\
\hline Butonlar & 3 & Start Stop & İnverterin kontrolünü harici bilgi sinyalleri ile çalıştırmak \\
\hline
\end{tabular}

Aynı zamanda eğitim simülatörü üzerine monte edilen harici pot ve butonlar, inverter cihazının uzaktan kontrolü uygulamaları için tasarlanmıştır. İnverter cihazının devreye alınması, hız ayarı ve parametre değişikliği bilgisayar kontrolu ile de yapılabilmektedir. Aynı zamanda İnverter cihazı ile motor devir kontrolü endüstriyel sensörlerin direkt olarak invertere bağlanıp sensörün okuduğu analog sinyal değerine göre motor devir kontrolü yapılabilir.

Inverter bağlantısı yukarıdaki bağlantı şemalarına göre gerçekleştirilir. Inverter cihazının girişine tek faz uygulanarak çıkışından üç fazlı gerilim almaktayız.

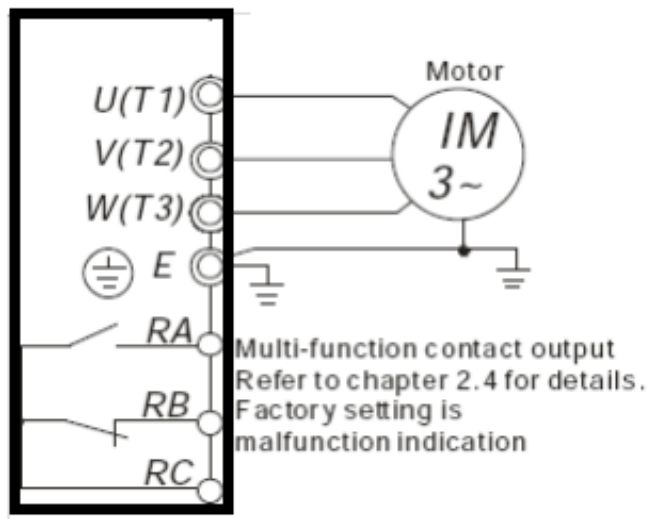

Şekil 14. İnverter bağlantı şeması

$\mathrm{R}$ ve $\mathrm{S}$ uçlarından tek fazlı enerji giriși yapılır. UVW uçlarına ise motor bağlantıları yapılır. MI, 
MI2, MI3, MI4... uçları cihazın kablolu bağlantı ile uzaktan kontrolü için kullanılır.+10 AVI ACM uçları harici potansiyometre bağlanarak hız kontrolü yapmak için kullanılır. RA RB RC uçları, cihazın role çıkışlarıdır. AFM ve acm uçları ise sürücü den analog çıkış sinyali almak için kullanılır.

\subsection{2. İnverter Sistemleri Eğitim Simülatörü Uygulaması}

2,2 KW bir üç fazlı motorun maksimum çalışma frekansını $50 \mathrm{~Hz}$ den $30 \mathrm{~Hz}$ değerine düşürmek, motorun start butonuna basildıktan sonra maksimum hızına ulaşma süresi 15 sn'den 3 sn, stop butonuna basildiktan sonra motorun tamamen durması için gerekli olan süreyi 20 sn değerinden 4 sn değerine, motor hızı harici bir potansiyometre kullanılarak inverterin $12 \mathrm{~m}$ uzağındaki bir panodan kontrol edilmek isteniyor. Uygun parametre ayarlarını yaparak motoru devreye almak istersek; öncelikle motor harici bir potansiyometre kullanılarak kontrol edilmek istenildiğinden simulator üzerinde bulunan harici potansiyometrenin üç ucu Şekil 10'da belirtildiği gibi kablo jackları yardımıyla invertere bağlantısı yapılır. Motorun uygulamada belirtilen özelliklerde çalışması için ise inverter cihazına aşağıda belirtilen parametre ayarlarının sırasıyla yapılması gerekir.

\begin{tabular}{|c|l|}
\hline 00.02 & 0:Parametre okunabilir/yazılabilir \\
Parametre & 1:Tüm parametre yalnızca okunabilir \\
Reset & 8:Keypad kilit \\
& 9:Tüm parametreler fabrika ayarına \\
& resetlenir.(50hz) \\
& 10:Tüm parametreler fabrika ayarına \\
& resetlenir,(60hz) \\
\hline
\end{tabular}

Mode tuşuna iki kez basılıp 00.02 parametre ayar menüsüne 10 değeri girilip inverter parametrelerinde daha önce yapılan herhangi bir değişiklik varsa fabrika ayarlarına dönüş yapılarak giderilmiş olur.

\begin{tabular}{|c|l|c|}
\hline \multicolumn{2}{|c|}{ Grup: 1 Temel Parametreler } \\
\hline \multirow{3}{*}{01.00} & Max çıkış & $50.00-$ \\
frekansı(fmax) & $600.00 \mathrm{hz}$ \\
\hline
\end{tabular}

Mode tuşuna iki kez basılıp 01.00 parametre menüsüne girilerek motor maksimum çalışma frekansı $30 \mathrm{HZ}$ değerine ayarlanır.

\begin{tabular}{|l|l|l|}
\hline 01.09 & HızlanmaZamanı 1 & $0.1-600.0$ saniye \\
\hline 01.10 & YavaşlamaZamanı 1 & $0.1-600.0$ saniye \\
\hline
\end{tabular}

Mode tuşuna iki kez basılıp 01.09 parametresinden motorun hızlanma zamanı 3 sn değerine, 01.10 parametre menüsünden motor durma süresi 4 sn değerine düşürülür.

\begin{tabular}{|l|l|l|}
\hline 02.00 & Birinci Ana Frekans & 0:Digital keypad \\
& Komutu Kaynağı & 1:0-+10V dan \\
& & 2:4-20mA AC dan \\
& & 3:RS-485 haberleşme den \\
& & 4:Digital keypad \\
& & \\
& & \\
\hline
\end{tabular}

02.00 parametre menüsünden harici pot ile kontrol için 1 değeri seçilerek harci potansiyometre üç telli kablo ile istenilen mesafeye taşınarak sistemin uzaktan kontrolü sağlanmış olur.

\subsection{Trafik Ișıkları Eğitim Simülatörü}

Trafik 1şıkları eğitim simülatörünün montajlı resmi Şekil 15'te gösterilmiştir. Sistemde kullanılan elemanların adetleri, teknik özellikleri ve bu elemanların görevleri Çizelge 7'de gösterilmiştir. $\mathrm{Bu}$ simülatör ile trafikte bulunan bir döner kavşağın taşıtlar ve yayalar için minyatür bir sinyalizasyonu gerçekleştirilmiştir. Mesleki eğitim alan bireyler PLC ya da mikro denetleyici kartları ile döner kavşak smilasyonunu gerçekleştirebilirler.

Sistemde kullanılan 1şıklandrma gereçleri, 24V DC gerilim ile çalışan led lambalardır. PLC ya da mikrodenetleyici kartlarının ilgili bağlantıları simülatörün born bağlantı uçlarına yapılarak istenilen şekilde çalıştırılması sağlanmış olur. Simülatör üzerinde taşıtlar için kırmızı sarı ve yeşil olmak üzere üç adet, yayalar için ise kırmızı ve yeşil olmak üzere iki adet led kullanılmıştır. 


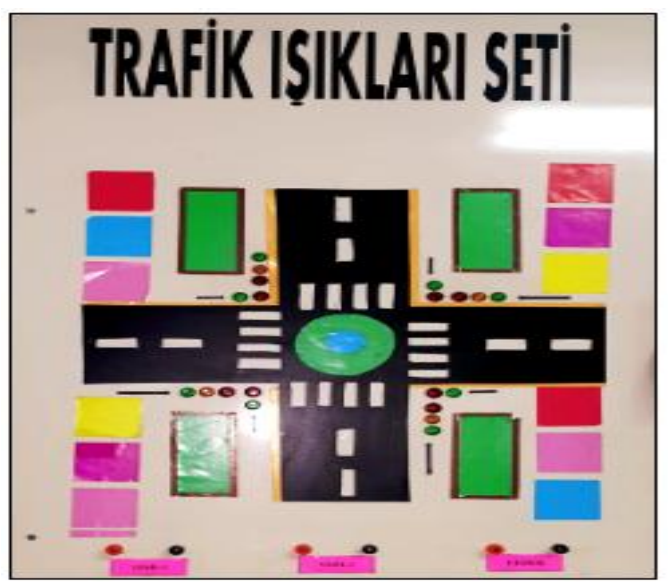

Şekil 15.Trafik işiklari eğitim simülatörünün montajli resmi

\subsubsection{Trafik Işııları Eğitim Simülatörü Uygulaması (PLC Yazilımı ile Çözüm)}

Bir döner kavşağın otomasyon sistemi gerçekleştirilmek isteniyor. Sistemde araçlar için sarı, kırmızı, yeşil uyarı 1şıkları ve yayalar için kırmızı ve yeşil uyarı 1şkıları kullanılacaktır. Araçlar için 30 saniye yeşil 1şık, 3 saniye sarı 1 şı yanıp sönecek ve sonra 20 saniye kırmızı 1 şık yanacaktır. Araçlara yeşil 1 şık yandığında yayalara kırmızı 1şı yanması, araçlara kırmızı 1şık yanıyor iken yayalara yeşil 1 şı yanması isteniyor. Uygun PLC ve Mikrodenetleyici yazılımı ile sistemi ayrı ayrı çalıştırmak istersek; PLC yazılımı ile çözüm Şekil 16'da gösterilmiştir.

Çizelge 7. Trafik işıkları eğitim simülatörü teknik özellikleri

\begin{tabular}{|c|c|c|c|}
\hline Malzeme Ad1 & Adet & Teknik özellik & Görevi \\
\hline Sinyal lambası & 20 & Kırmızı Sarı Yeşil 24V DC & Yönlendirme için uyarı 1şı̆ı sağlamak \\
\hline Born Vidası & 40 & $0,9 \mathrm{~mm}$ & $\begin{array}{c}\text { Sinyal lambaları çalışması için gerekli olan } \\
\text { enerji kaynağı girişlerini sağlamak }\end{array}$ \\
\hline
\end{tabular}

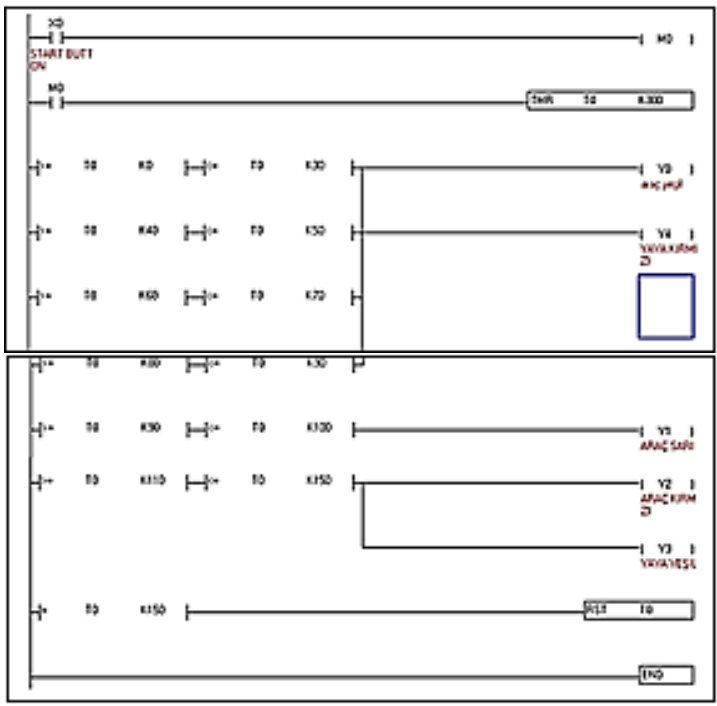

Şekil 16. PLC yazılımı ile çözüm

Sistemde $\mathrm{x} 0$ start butonu ile çalıștırılmaya başlanıyor. Yönlendirme 1şıklarının çalıştırılması ve çalışma sürelerinin kıyaslanabilmesi için timer komutu kullanılmıştır. Timer komutundan okunan anlık zaman değerleri, lambaların yanma süreleri ve karşılaştırma komutları ile kıyaslanarak yönlendirme 1şıkları aktif veya pasif edilebilmektedir. Programın bir döngüyü tamamladıktan sonra ikinci döngüye geçmesi için timer son satırda resetlenmiştir.

\subsubsection{Trafik Ișıkları Eğitim Simülatörü Uygulaması (Mikrodenetleyici Yazılımı İle Çözüm)}

Mikrodenetleyici örnek yazılımında b portları çıkış portu olarak seçilmiştir. Portlar ise b0 araç yeşil, b1 araç sarı, b2 araç kırmızı; b3 yaya yeşil, b4 yaya kırmızı olarak seçilmiştir. Așağıdaki simülatör yazılımı ile program test edilip daha sonra kontrol kartındaki entegreye program yüklenerek eğitim simülatörüne gerekli bağlantılar yapılarak trafik 1șıkları otomasyonu çalışması gözlemlenebilir. Mikrodenetleyici simülatör programı örneği Şekil 17'de gösterilmiştir. Ayrıca zamana bağlı 1şı yanma süreleri Çizelge 8 'de gösterilmiștir. 


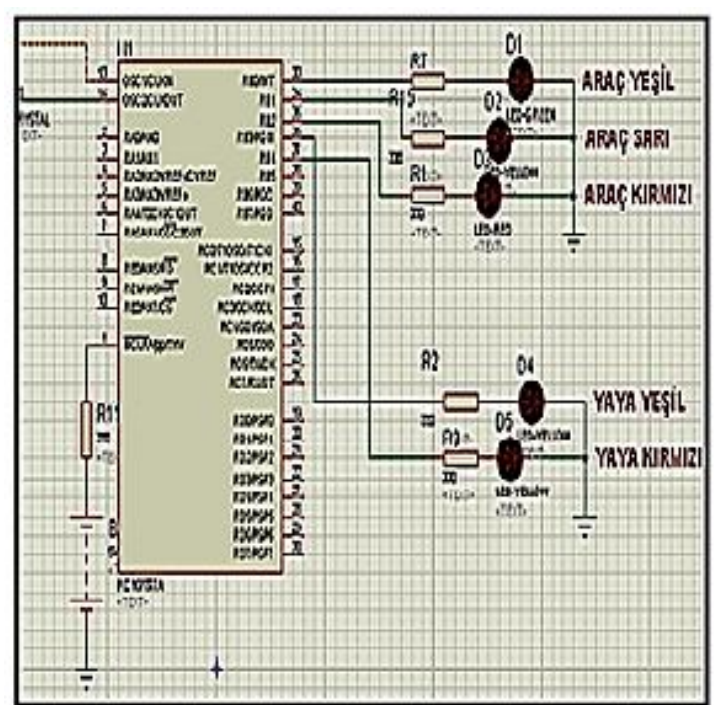

Şekil 17. Mikrodenetleyici simülatör programı örneği
Mikrodenetleyici yazılımını gerçekleştirmek için öncelikle yukarıdaki program tablosu oluşturulur. Böylece hata yapılma ihtimali düşürülmüş olur. Sisteme ait mikrodenetleyici yazılımı aşağıda verilmiştir.

\#include <16F877A.h>

\#fuses XT,NOWDT,NOPROTECT

\#use delay (clock=4000000)

void main()

\{

tekrar:

set_tris_b(0b00000000);//portları çıkış output_b $(0)$;

output_b(17);//araç yeşil yaya kırmızı delay_ms(3000); ///3sn bekle

Çizelge 8. Trafik işıkları eğitim simülatörü ışık süre tablosu

\begin{tabular}{|c|c|c|c|c|c|c|}
\hline Açıklama & $\begin{array}{l}\text { Zaman aralığ1 } \\
32\end{array}$ & $\begin{array}{c}\text { Yaya } \\
\text { k1rmiz1(b4) } \\
16\end{array}$ & $\begin{array}{c}\text { Yaya } \\
\text { Yeşil(b3) } \\
8 \\
\end{array}$ & $\begin{array}{c}\text { Araç Kırmız1 } \\
\text { (b2) } \\
4\end{array}$ & $\begin{array}{c}\text { Araç Sar1 } \\
\text { (b1) } \\
2 \\
\end{array}$ & $\begin{array}{l}\text { Araç } \\
\text { Yeşil } \\
\text { (b0) } 1 \\
\end{array}$ \\
\hline Araç yeşil (17) & $3 \mathrm{sn}$ & 1 & 0 & 0 & 0 & 1 \\
\hline Yeşil yan son (16) & $1 \mathrm{sn}$ & 1 & 0 & 0 & 0 & 0 \\
\hline Yeşil yan son (17) & $1 \mathrm{sn}$ & 1 & 0 & 0 & 0 & 1 \\
\hline Yeşil yan son (16) & $1 \mathrm{sn}$ & 1 & 0 & 0 & 0 & 0 \\
\hline Yeşil yan son (17) & $1 \mathrm{sn}$ & 1 & 0 & 0 & 0 & 1 \\
\hline Araç sarı (18) & $1 \mathrm{sn}$ & 1 & 0 & 0 & 1 & 0 \\
\hline $\begin{array}{l}\text { Araç k1rmızı yaya } \\
\text { yeşil (12) }\end{array}$ & $3 \mathrm{sn}$ & 0 & 1 & 1 & 0 & 0 \\
\hline Başa dön & & & & & & \\
\hline
\end{tabular}

output b(16);///yeșil yan son delay_ms(1000);

output_b(17);///yeşil yan son

delay_ms(1000);

output_b(16);///yeşil yan son

delay_ms(1000);

output_b(17);//yeşil yan son

delay_ms(1000);

output b(18);//araç sarı yan

delay_ms(1000);

output_b(12);//araç kırmızı yay yeşil

delay_ms(3000); //3sn bekle

goto tekrar;// başa dön

\}

Ç.Ü.Müh.Mim.Fak.Dergisi, 31(1), Haziran 2016

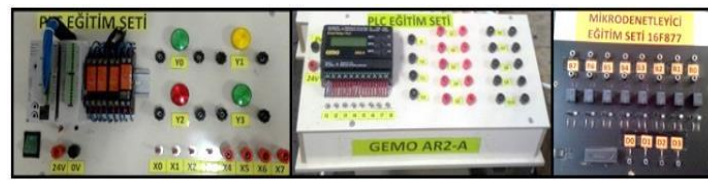

Şekil 18. Simülatör uygulamalarında kullanılan harici programlama cihazları (PLC ve mikrodenetleyici)

Otomasyon sistemleri uygulamaları eğitim simülatörü, endüstride kullanılan üretim cihazlarının kimi zaman minyatürü, kimi zaman da gerçek boyutlusu kullanılarak öğrenci ve 
kursiyerlerin bu materyalleri tanıma ve kullanma olanağı bulduğu, aynı zamanda PLC ya da mikodenetleyici kartları ile farklı program algoritmaları gerçekleştirerek deneysel çalışmalar yaptığı bir düzenektir. Şekil 18 'de sistem kontrolünde kullanılan PLC ve mikrodenetleyici kartları görülmektedir $[7,8]$.

\section{TARAŞTIRMA BULGULARI VE TARTIŞMA}

Türkiye'de en büyük sorunlardan birisi işsizlik değil mesleksizlik ve mesleki eğitim seviyesinin düşüklüğüdür. Herkes tarafindan bilinen ve basında paylaşılan araştırma sonuçlarına göre; İstanbul genelinde 8500 , Türkiye genelinde 10000 'in üzerinde işyeri ile görüşülmüştür. Yalnızca İstanbul'da 8500 işyerinin ortalama yüzde yirmisinde açık iş var. Her işyerinin yüzde otuzbeşi de 'aradığım niteliklerde iş gücü bulamıyor. İş için müracat eden insanların \%65'i 'yeterli deneyim ve beceriye sahip değil'. İş başvurusunda bulunanların \%54'ü ise 'yeterli eğitime sahip değil. Bir yanda işsizlik diğer yanda iş gücü talebi var ama talebi karşılayacak bir program henüz tam anlamıyla oturmadı. Işveren ne iş olsa yapacak adam istemiyor.

Son yıllarda bu sorunları ortadan kaldırmak için İSKKUR iş ve meslek danışmanları aracılığıyla işletmelerin hangi tür elemana ihtiyacı olduğunu belirliyor, mesleki kurslar açıyor, teşvik veriyor ve işe yerleştiriyor. Son yıllarda yapılan çalışmalarla Meslek Liseleri ve Meslek Yüksekokullarının yeniden yapılandırılarak piyasa ihtiyaçlarına uygun yetişmiş elemanları hazırlaması beklenmektedir. Geliştirilen bu eğitim seti, öğrencilerin teorik öğrenmelerini uygulama ile desteklemiş; mezun olan öğrencilerin iş ortamlarında aldıkları bu eğitim sayesinde mesleki yeterliliklerinin artarak alanlarındaki arıza ve sorunları daha kolay ve çabuk çözümledikleri gözlenmiştir $[9,10]$.

\section{SONUÇ}

Mesleki ve Teknik Eğitimde etkin bir öğrenme ortamı oluşması için teorik bilgilerin uygulama örnekleri ile desteklenmesi gerekmektedir. Aksi takdirde teknik eğitim alan bireylerin mesleki özgüvenleri yeterli seviyeye ulaşmamaktadır. Bu güven eksikliği mesleki eğitim alan bireylerin eğitim aldıkları alanda çalışmak istememesi ve mesleğini sevmemesi gibi olumsuz durumlar doğurmaktadır. Mesleki ve teknik eğitimde öğrenci ve kursiyerlerin uygulama faaliyetleri ile teorik bilgilerinin sürekli pekiştirilmesi mümkünse endüstri ortamında kullanacakları teknik gereçleri kullanmalarının tam kavranmaları için her branşa göre uygun eğitim simülatörlerinin geliştirilmesi çok önemlidir. Otomasyon sistemleri uygulamaları eğitim simülatörü, bu amaçla geliştirilen bir eğitim simülatörüdür. $\mathrm{Bu}$ simülatör ile birden fazla üç fazlı elektrik motorunun ileri-geri kontrolü, endüstriyel sensörlerin gerekli bağlantıları yapılarak çıkış bilgisinin alınıp işlenerek başka bir alıcinın kontrol edilmesi, proses kontrol cihazlarına herhangi bir sensör bağlayarak sensor bilgisinin okunup set parametre değerleri girilerek başka bir elektriksel alıcıyı çalıştırması, birbirinden bağımsız çalışan çift etkili pnömatik silindirlerin elekriksel uyartımla çalışan valfler ile kontrölü, üç fazlı asenkron bir motorun motor sürücüsü ile istenilen devirde kontrolü, motorun hızlanma zamanı, yavaşlama zamanı, uzaktan kontrolü, bilgisayar ile devir kontrolü, parametre değişikliği, döner bir kavşağın trafik sinyalizasyonunun gerçekleştirilmesi gibi yüzlerce birbirinden farklı uygulama, PLC cihazı ve mikrodenetleyici kartlar programlanarak gerçekleştirilebilmektedir.

Sonuç olarak bu eğitim simülatörü, bu konuda yetiştirilecek teknik elemanın yetişmesine büyük katkıda bulunacak, mesleki ve teknik eğitimini tamamlamış teknik elemanların da kendilerini geliştirmelerinde büyük fayda sağlayacaktır. Ayrıca bu simülatör, teknik elemanda sektörün ihtiyacı olan teknik temel becerilerinin kazanılması ihtiyacını büyük ölçüde giderecektir.

\section{KAYNAKLAR}

1. Yörük, S., Dikici, A., Uysal, A., 2002. Bilgi Toplumu Ve Türkiye'de Mesleki Eğitim, Fırat Üniversitesi Sosyal Bilimler Dergisi, Cilt 12,

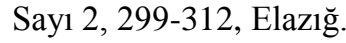


2. TİSK, 1997. Türkiye'de ve Dünyada Mesleki Eğitim, Ankara.

3. Akpınar, B., 2005. Teknik Öğretmen Yetiştirme Sorunu ve Teknik Eğitim Fakültelerinin Geleceği, GÜ, Gazi Eğitim Fakültesi Dergisi, Cilt 25, Sayı 1, 259-274, Ankara.

4. Karacan, S., Karacan, E., 2004. Meslek Yüksekokullarında (MYO) Yapılan Staj Uygulamalarına İlişkin Bir Araştırma: Kalite ve Verimlilik İçin İş Yerleri-MYO İşbirliğinin Gereği, Kocaeli Üniversitesi Sosyal Bilimler Enstitüsü Dergisi, 168-184, Kocaeli.

5. Şimşek, E., Bilgili, M., Küçükatay, O., 2015. Programlanabilen Mantiksal Denetleyici (Plc) İle Çalişan Split Klima Tasarimi, 1.Endüstriyel Otomasyon Kongre Ve Sergisi , Adana, Türkiye, 14-16 Mayıs, Cilt.1, no.E/MMO/642, Sayfa 143-156, Adana.

6. Akçali, İ., D., 1999. Otomatik Kontrol, Ç.Ü. Mactimarum Yayın No: 9, Adana.

7. http://www.gemo.com.tr/ 7.01.2016 tarihinde erişildi.

8. http://www.fastltd.com/ 07.01.2016 tarihinde erişildi.

9. http://haber.star.com.tr/ekonomi/eleman- varama, 9.02.2016 tarihinde erişildi.

10. http://www.iskur.gov.tr/isarayan/kursarama.asp x 09.012. 2016 tarihinde erişildi. 
